\title{
Sensing Earth and environment dynamics by telecommunication fiber-optic sensors: an urban experiment in Pennsylvania, USA
}

\author{
Tieyuan Zhu ${ }^{1,2}$, Junzhu Shen ${ }^{1}$, and Eileen R. Martin ${ }^{3}$ \\ ${ }^{1}$ Department of Geosciences, Pennsylvania State University, State College, USA \\ ${ }^{2}$ EMS Energy Institute, Pennsylvania State University, State College, USA \\ ${ }^{3}$ Department of Mathematics, Virginia Tech, Blacksburg, USA
}

Correspondence: Tieyuan Zhu (tyzhu@psu.edu)

Received: 5 June 2020 - Discussion started: 29 June 2020

Revised: 1 December 2020 - Accepted: 5 December 2020 - Published: 28 January 2021

\begin{abstract}
Continuous seismic monitoring of the Earth's near surface (top $100 \mathrm{~m}$ ), especially with improved resolution and extent of data both in space and time, would yield more accurate insights about the effect of extreme-weather events (e.g., flooding or drought) and climate change on the Earth's surface and subsurface systems. However, continuous longterm seismic monitoring, especially in urban areas, remains challenging. We describe the Fiber Optic foR Environmental SEnsEing (FORESEE) project in Pennsylvania, USA, the first continuous-monitoring distributed acoustic sensing (DAS) fiber array in the eastern USA. This array is made up of nearly $5 \mathrm{~km}$ of pre-existing dark telecommunication fiber underneath the Pennsylvania State University campus. A major thrust of this experiment is the study of urban geohazard and hydrological systems through near-surface seismic monitoring. Here we detail the FORESEE experiment deployment and instrument calibration, and describe multiple observations of seismic sources in the first year. We calibrate the array by comparison to earthquake data from a nearby seismometer and to active-source geophone data. We observed a wide variety of seismic signatures in our DAS recordings: natural events (earthquakes and thunderstorms) and anthropogenic events (mining blasts, vehicles, music concerts and walking steps). Preliminary analysis of these signals suggests DAS has the capability to sense broadband vibrations and discriminate between seismic signatures of different quakes and anthropogenic sources. With the success of collecting 1 year of continuous DAS recordings, we conclude that DAS along with telecommunication fiber will potentially serve the purpose of continuous near-surface seismic monitoring in populated areas.
\end{abstract}

\section{Introduction}

As increasingly more people reside in urban areas, and as climate change leads to more extreme weather patterns, we need more reliable data to understand the Earth's surface and subsurface systems and design appropriate strategies to estimate risks and reduce the vulnerability of people in cities. The upper $100 \mathrm{~m}$ of the subsurface, also called the critical zone or near surface, is a major driving factor behind geological and hydrological systems' behaviors and is the layer that most affects stability of infrastructure and buildings. However, near-surface Earth materials driven by multiscale physical, chemical and biological processes are extremely heterogeneous, varying spatially at the scale of meters or even smaller and temporally from milliseconds (or less) to millions of years. This suggests that dense and continuous measurements that can yield spatiotemporal information are particularly valuable, and such data could be provided by a dense and (semi)permanent deployable seismic array.

Despite their expected utility for real-time monitoring of subsurface environmental systems, neither temporary nor permanent dense seismic geophone arrays have been widely deployed in urban areas. The primary limiting factors in deploying traditional seismic monitoring include restrictions on human-controlled sources in densely populated areas, difficulty obtaining permission and space to deploy sensors near civil infrastructure, challenges in securing sensors against theft or vandalism, and high costs to maintain power and data transfer from geophones.

While traditional seismic monitoring is infeasible in urban areas, a rapidly developing technology, fiber-optic dis- 
tributed acoustic sensing (DAS), provides a promising alternative. The DAS technique repurposes a standard fiber-optic cable with an attached laser interrogator unit as an array of dense pseudo-seismometers measuring vibrations by repeatedly probing the axial strain rate at all points along the entire fiber (Parker et al., 2014). DAS was initially applied to geophysical applications to record active seismic sources in rural or offshore areas for oil and gas exploration and monitoring, as well as seismic monitoring of $\mathrm{CO}_{2}$ sequestration (Daley et al., 2013). Later, DAS was applied for near-surface shear wave imaging (Dou et al., 2017), permafrost thaw monitoring (Ajo-Franklin et al., 2017; Martin et al., 2016) and monitoring water table levels (Ajo-Franklin et al., 2019).

Several experiments in California have been carried out by teams using existing telecommunication infrastructure. By using existing telecommunication infrastructure, particularly by plugging into "dark" or unused fiber that is already installed underground, these experiments greatly reduce the experimental cost and setup time as an interrogator simply needs to be plugged into one end of a stretch of fiber to begin data acquisition. This series of experiments has shown that signal quality is often good enough for earthquake detection and imaging even though loose cables in underground conduits only couple to the surrounding soils through friction and gravity (Lindsey et al., 2017; Jousset et al., 2018; Martin et al., 2019; Yu et al., 2019; Ajo-Franklin et al., 2019). At the Stanford Fiber Optic Seismic Observatory, Rayleigh wave dispersion showed significant spatial variability at scales relevant to earthquake ground motion prediction (Martin, 2018; Spica et al., 2020) and time-lapse changes through a building excavation (Fang et al., 2020). However, investigation of near-surface time-lapse changes due to seasonal precipitation variation yielded no significant velocity variation when investigated with time-lapse ambient-noise interferometry (Martin, 2018).

In this study we introduce the Penn State Fiber Optic foR Environmental SEnsEing (FORESEE) project. The ultimate goal of this project is to understand the response of DAS fiber sensing arrays to particular events and use repeating signals to continuously monitor environment and subsurface physical, chemical and biological changes. Similar to the Stanford array (Martin, 2018) and recent Pasadena array (Zhan, 2020), the Penn State FORESEE array has continuously recorded DAS data along $5 \mathrm{~km}$ of dark underground telecommunication fibers for over 1 year since April 2019 (Zhu and Stensrud, 2019). This is the first deployment of a DAS dark-fiber array in the eastern USA.

This new experiment will not only improve our understanding of the reproducibility of results across varied installation types but will also provide several new opportunities. Firstly, soil and shallow bedrock in the Allegheny Mountains region creates complex near-surface geophysical properties with strong heterogeneity (Brantley et al., 2013). Secondly, strong seasonal variations in temperature and precipitation yield a unique opportunity for understanding the sensitivity of DAS to temperature and groundwater level fluctuation. In addition, karst geology systems in most of Pennsylvania (PA) evolve through hydrologic processes. The underlying carbonate bedrock can be slowly dissolved by circulating groundwater, which can form sinkholes and caverns causing potential hazards on relatively short geologic timescales (Bansah, 2018). Especially in urban areas, sinkhole collapse and subsidence issues can be extreme threats to human safety and property (Weary, 2015). In terms of earthquake research, although the eastern USA typically experiences less seismicity, the underlying bedrock is older, harder and often denser than in the western USA, which allows seismic waves to propagate more efficiently in the event of an earthquake. In addition, eastern cities are geographically dense and have many older structures built before the 1970s, which were not designed to endure earthquakes. More extensive sensor systems will benefit the characterization of regional earthquake hazards.

In this paper, we detail the field deployment of the FORESEE array. Then we report a variety of interesting signals, including global and regional earthquakes, thunder-induced quakes (thunderquakes; Zhu and Stensrud, 2019), and mining blasts. Further, we show some surprising anthropogenic noise recordings: footsteps and live music. We conclude with discussion of these data and the important role they may play in understanding the subsurface and infrastructure.

\section{Experiment overview}

In designing the array, we had several goals: high resolution to detect small-scale subsurface features, long aperture to increase coverage of the area and increase the likelihood of sensing near a feature of interest, ease of access following existing telecommunication fiber paths, and including at least two directions. Considering these aims, we selected the fiber route pictured in Fig. 1a, consisting of two fiber-optic sections spliced together (around channel 1340), with a total fiber length of approximately $5 \mathrm{~km}$. These fibers are all underneath the Pennsylvania State University campus, and this experiment used a single strand of fiber optics in each cable. These cables were already being used for telecommunication purposes, but not all strands were previously in use (so-called "dark fiber"). These cables were sitting in buried concrete conduits at a depth of roughly $1 \mathrm{~m}$, as pictured in Fig. $1 b$.

The DAS measurements are recorded by a Silixa iDAS2 interrogator unit, pictured in Fig. 1a, which is connected to one end of the fiber using an E2000 APC connector. The DAS array made continuous strain rate measurements at a $500 \mathrm{~Hz}$ sampling frequency with a $10 \mathrm{~m}$ gauge length and $2 \mathrm{~m}$ channel spacing. We began recording data on 5 April 2019 , and the recording is still running at the time of paper submission. 
(a)

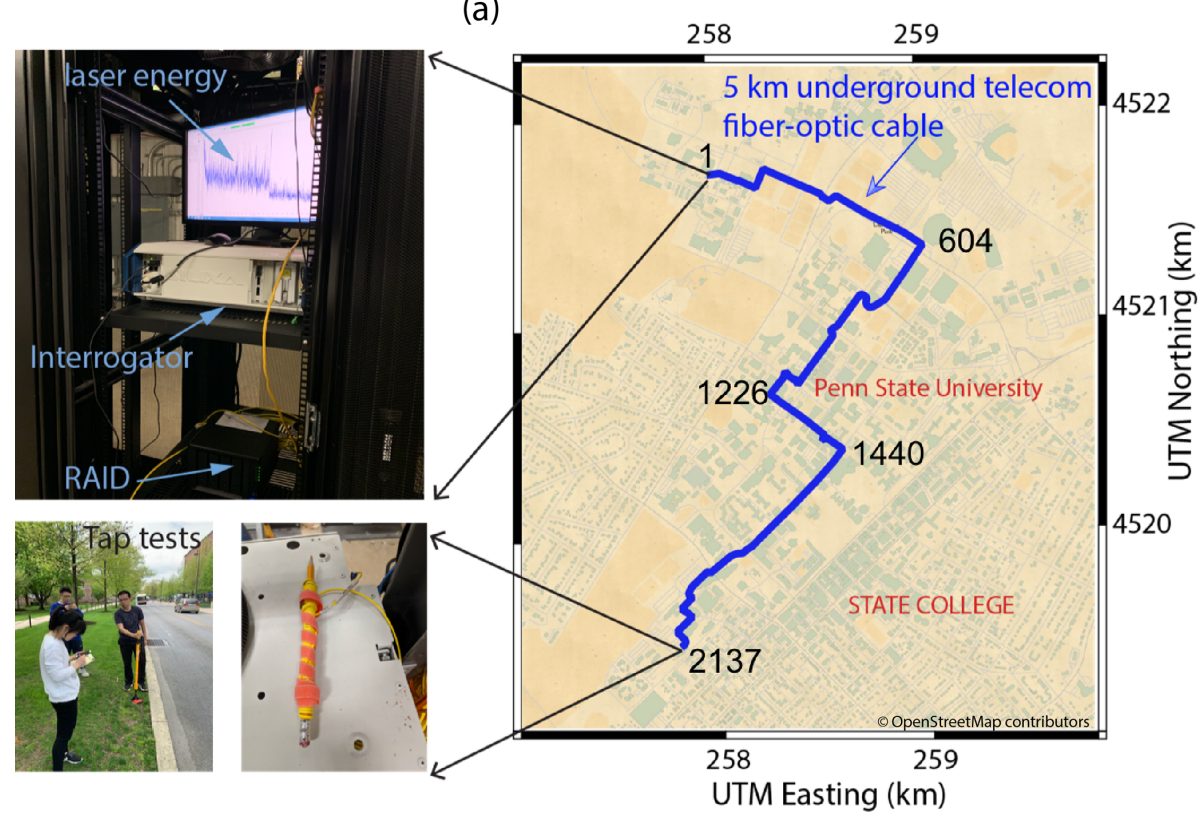

(b)

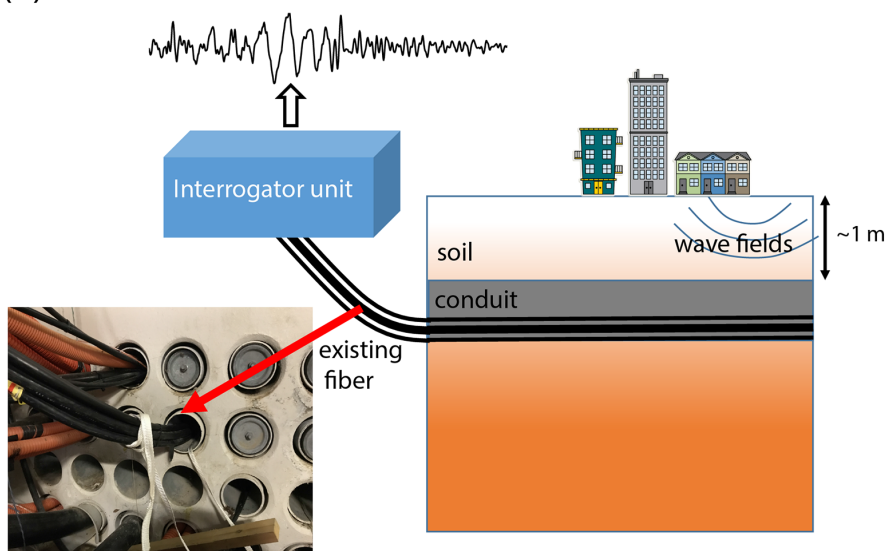

Figure 1. (a) Penn State fiber-optic distributed acoustic sensing (DAS) array map. Numbers listed along the array denote the channel number. Top left: DAS field setup; bottom left: a photo of tap tests; bottom right: the fiber end. (b) Illustration of DAS array connecting existing fiber optics. The bottom left subfigure shows the pre-existing fiber-optic cable (in black) used for this project. Map () OpenStreetMap contributors 2020. Distributed under a Creative Commons BY-SA License.

\subsection{Data storage}

Because this experiment generated many tens of terabytes of data, we connected the DAS interrogator unit to a networkattached storage (NAS) server. The server was connected to an internet network, providing us with remote data access in real time. The interrogator and NAS were hosted in a Penn State IT building connected with an uninterruptible power supply (UPS) for backup power in case of station power interruption. Figure 1 (top left panel) shows the setup of the DAS system of the FORESEE pilot experiment in a standard computer rack. A GPS clock and antenna were connected for precise timing. We installed the GPS antenna outside of the building, roughly $2.0 \mathrm{~m}$ above the ground. Raw DAS record- ings are saved in TDMS format (Silixa iDAS default data format, for which Silixa provides MATLAB and Python reader scripts). The selected DAS recording settings yielded over $200 \mathrm{~GB} \mathrm{~d}^{-1}$ and ultimately about $76 \mathrm{~TB}$ of raw data per year.

\subsection{Determination of sensor locations}

Before any seismic array processing, we needed to determine the precise location of each sensor along the fiber. Because the fiber sits in underground conduits, it is invisible from the surface, so traditional methods of obtaining GPS coordinates at individual surface seismic sensors were not feasible. Penn State's Enterprise Networking and Communication Services department manages the cable, so they provided a map of the fiber cable path and telecommunication manholes visible at 


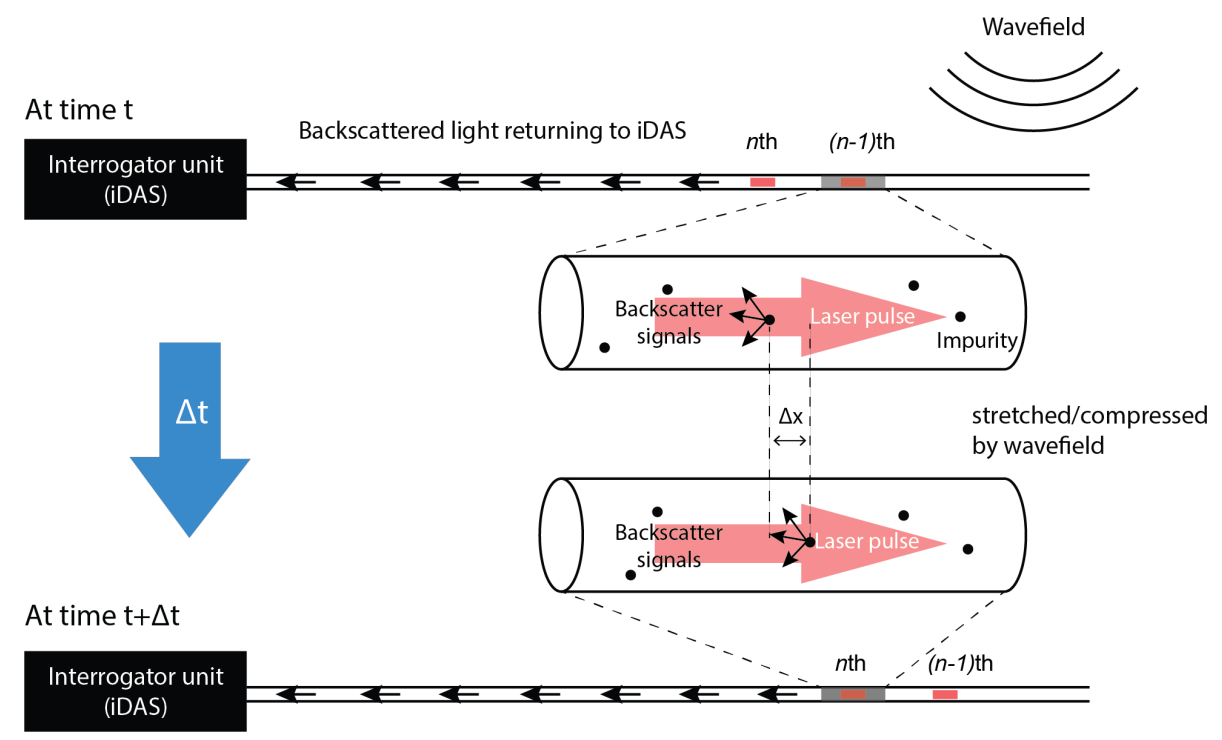

Figure 2. Principle of DAS. Rayleigh backscattering occurs at anomalies in the optical fiber which can be shifted by the surrounding wavefield. The phase changes of successive pulses are recorded by the iDAS instrument.

the surface. Following this map, we ran tap tests to determine a set of representative channel indices at particular locations. For each location, we used a hammer drop source to generate six distinguished shots on the ground. Ideally the channel centered around a shot will respond most strongly to the shot and correspond to the GPS position of the hammer source. At many locations, strong noise inhibited our ability to identify hammer shots in raw DAS data. Instead, we computed the spectral energy, applying the Fourier transform to windowed trace by a short sliding window. (Martin, 2018; Zhu and Stensrud, 2019). As seen in Fig. 5b, the hammer shots are easily identified and the center channel is relatively unambiguous. We refer readers to our previous work for examples (Zhu and Stensrud, 2019). We ran more than 101 tap tests to obtain the positions of 101 channels. Finally we used interpolation to estimate locations of all 2137 channels with $2 \mathrm{~m}$ spacing. Note that some channels were removed from analysis after determining locations where fiber was looped back on itself.

\subsection{DAS calibration to seismometers}

To verify that this DAS system (interrogator, fiber and cable in conduit) records a useful metric of ground motion, we convert our DAS recordings to particle velocity and compare to the nearest broadband seismometer. This calibration procedure is based on several previous studies (Daley et al., 2016; Wang et al., 2018; Lindsey et al., 2020a). To ensure this paper is self-contained, we briefly review this procedure.

The interrogator that we used records axial strain rate in the direction of the cable. Specifically, the actual output of the DAS system is the phase changes between consecutive pulses during the laser repetition rate (Fig. 2). The phase of light traveling a distance $x$ in a cable with refractive index $n$ can be expressed as

$\Phi=\frac{4 \pi n x}{\lambda}$.

The wavelength of Rayleigh backscattered light equals the incident wavelength $(1500 \mathrm{~nm})$. We assume refractive index changes linearly with strain rate $\left(\frac{\Delta n}{n}=(\zeta-1) \frac{\Delta x}{x}\right)$. The scalar multiplicative factor $(\zeta)$ is determined by the material properties: $\zeta=0.735$ for single-mode fiber glass with light propagating inside. Hence the phase changes at the same fiber section separated by the gauge length $L_{\mathrm{G}}$ (e.g., $L_{\mathrm{G}}=10 \mathrm{~m}$ ) can be expanded as

$$
\begin{aligned}
\Delta \Phi & =\frac{\partial \Phi}{\partial x} x+\frac{\partial \Phi}{\partial n} n=\frac{4 \pi n x}{\lambda x} \Delta x+\frac{4 \pi n x}{\lambda n} \Delta n \\
& =\frac{4 \pi n L_{\mathrm{G}}}{\lambda}\left(\frac{\Delta x}{x}+\frac{\Delta n}{n}\right)=\frac{4 \pi n \zeta L_{\mathrm{G}} \Delta x}{\lambda x} .
\end{aligned}
$$

After rearranging the equation above, we can link raw DAS output (strain rate in iDAS) to strain rate $\dot{\epsilon}_{x x}$ by applying a constant scaling factor as follows:

$$
\begin{aligned}
\dot{\epsilon}_{x x} & =\frac{\lambda}{4 \pi n \zeta L_{\mathrm{G}} \mathrm{d} t} \Delta \Phi \\
& =\frac{1500 \times 10^{-9}(\mathrm{~m})}{4 \pi \times 1.445 \times 10(\mathrm{~m}) \times 0.735 \mathrm{~d} t} \Delta \Phi \\
& =11.6 \times 10^{-9} f_{\mathrm{s}} \Delta \Phi,
\end{aligned}
$$

where $f_{\mathrm{s}}=1 / \mathrm{d} t$ is the sampling frequency and $\mathrm{d} t$ is the time sampling rate. The strain rate $\dot{\epsilon}_{x x}$ is expressed in terms of strain per second. Note that the raw DAS output $\Delta \Phi$ can be different in terms of optical unit (either phase change or phase change rate), depending on the instrumental setup (Lindsey et al., 2020a). 
(a)

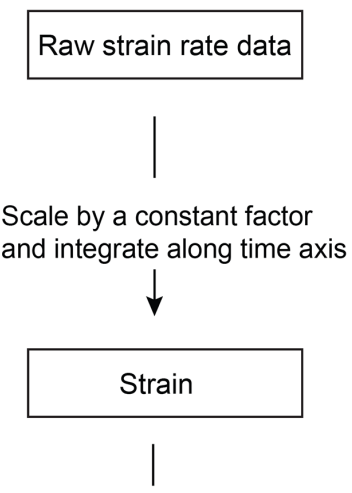

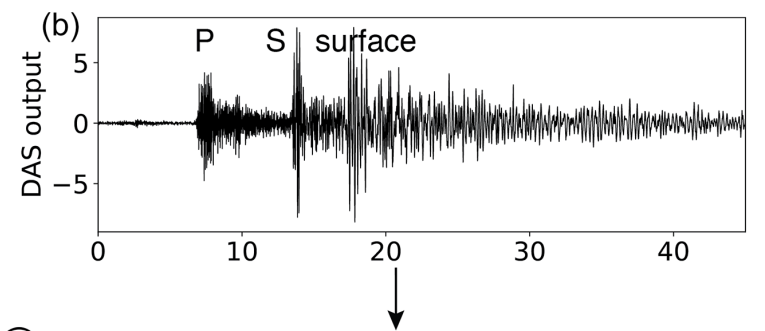
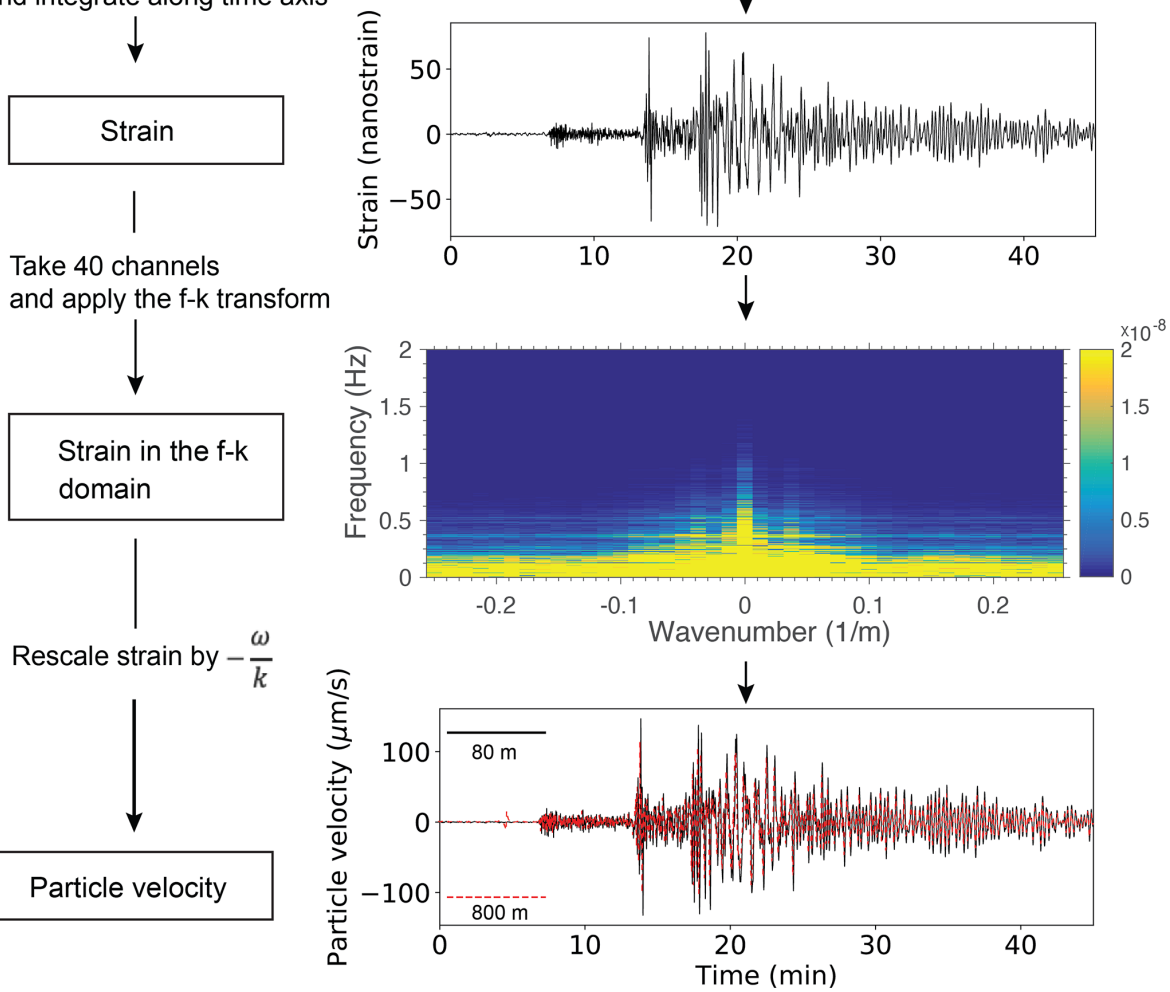

Figure 3. (a) Workflow of converting DAS measurements to particle velocity; (b) an example of the Peru M 8.0 earthquake to demonstrate the workflow step by step.

To illustrate the calibration procedure, we take the Peru M 8.0 earthquake on 26 May 2019 as an example to convert DAS recordings to particle velocity. We chose over 80 channels of an L-shape subarray with 40 channels in each direction, shown in Fig. 4. Traces from the DAS cable segment of the same orientation are compared with one horizontal component rotated to the cable direction of a nearby seismic station (SSPA) about $17.7 \mathrm{~km}$ away. This distance would be too far for a comparison in response to a local seismic source, but this teleseismic event is expected to yield similar responses by seismometers at this distance. Figure 3 shows individual steps to convert strain rate to particle velocity. First we multiply the raw data $\Delta \Phi$ by a constant scaling factor $\left(11.6 f_{\mathrm{s}}\right)$ to obtain the strain rate (nanostrain per second). The strain rate is integrated along the time axis to obtain the strain. Lowfrequency artifacts resulting from integration are removed by applying a band-pass filter between 0.02 and $0.5 \mathrm{~Hz}$. Then DAS array strain values are converted to particle velocity by scaling the apparent velocity $c$ (Daley et al., 2016; Wang et al., 2018) as follows:

$v=\frac{\partial u}{\partial t}=-c \frac{\partial u}{\partial x}=-\frac{\omega}{k} \frac{\partial u}{\partial x}=-\frac{\omega}{k} \epsilon_{x x}$,

where $c$ is the apparent phase velocity along the cable axial direction. In the test, we apply the $f-k$ transform of the seismograms and scale Fourier coefficients by $V(\omega, k)=$ $-\frac{(\omega+\sigma) E(\omega, k)}{(k+\sigma)}$, where $\sigma$ is the threshold to avoid instabilities in division by zero frequency and wavenumber values (Lindsey et al., 2020a). Finally we apply inverse Fourier transform to $V(\omega, k)$ to get particle velocity in the time domain.

Here we use 40 traces (with coherent waveforms) for the $f-k$ transform. Then we select one best $\sigma=1 \times 10^{-5}$ by trial and error for matching particle velocity waveform. We note that the waveform matching is somehow dependent on the threshold number $\sigma$ (Lindsey et al., 2020a), which may arise from an ambiguous velocity factor determined by the $f-k$ transform with limited offset in the case of plane wave. We also include a longer offset $(800 \mathrm{~m})$ (maximum in the fiber 


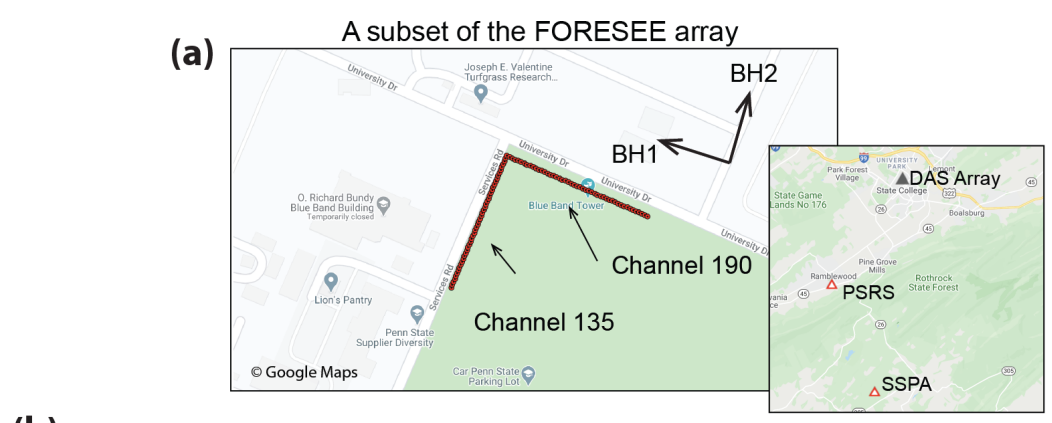

(b)

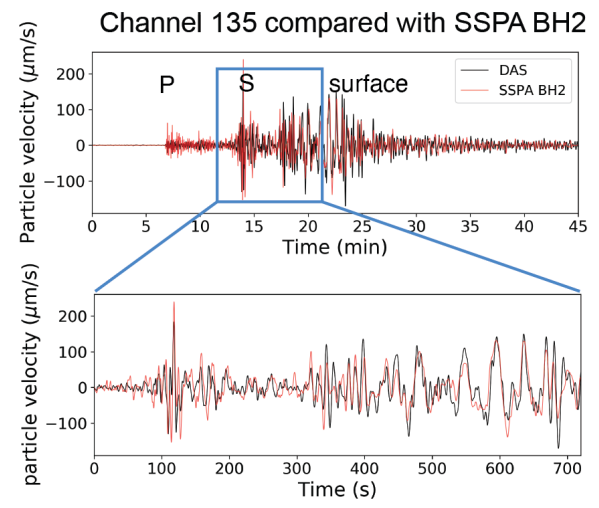

(c)

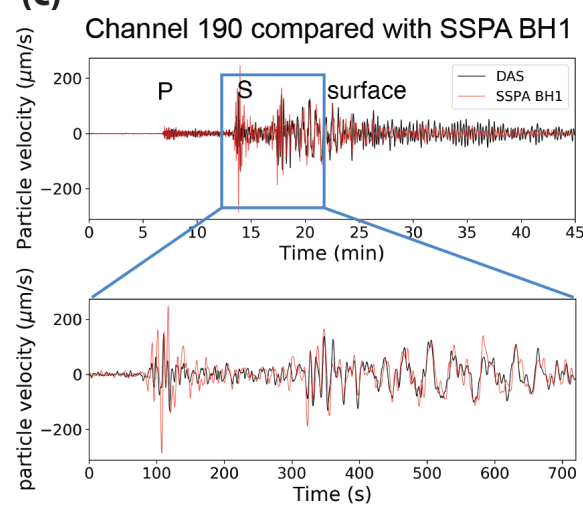

Figure 4. (a) Locations of 80 channels of the fiber array we used for calibration. Top shows the azimuth of two horizontal channels of SSPA, a nearby seismometer $17.7 \mathrm{~km}$ away. (b) Comparison of channel 135 (black) with BH2 component of SSPA (red). (c) Comparison of channel 190 (black) with BH1 component of SSPA (red).

direction avoiding the turning point) with $\sigma=1 \times 10^{-3}$. Although the waveforms are highly varying between channels due to possible coupling effects, the resulted particle velocity is very close (see red trace in the bottom panel in Fig. 3). We refer readers to Wang et al. (2018) and Lindsey et al. (2020a) for details of the $f-k$ conversion method.

Figure 4 shows the comparisons of DAS recordings in two orthogonal directions (Fig. 4a) to reference seismograms (BH1 and BH2) (particle velocity in $\mu \mathrm{ms}^{-1}$ ) at the nearest seismic station (SSPA) after applying a band-pass filter $(0.02-0.5 \mathrm{~Hz})$. It is clear that the DAS data show an agreement with the reference seismogram (particularly $S$ wave in BH2). Small inconsistencies in coda wave amplitudes are possibly due to the DAS data representing the average signals over a gauge length rather than an isolated point sensor (Wang et al., 2018), although many other factors may play a role in waveform differences, such as different locations of the seismic station and DAS array, directional sensitivity, unknown DAS instrument response, and the host environment. Overall, this calibration process suggests that this DAS array is an acceptable system for recording single-component low-frequency seismic data.

To calibrate higher frequencies, we performed a similar comparison using an active source, shown in Fig. 5. We colocated a 24-channel geophone array (4 m spacing) on the ground just above the fiber cable. After synchronizing the
GPS timing, we searched for DAS shot gather recordings. We applied a band-pass filter $(10-60 \mathrm{~Hz})$ and auto-gain control (AGC) to geophone and DAS data. In the geophone data, we identified a direct wave $\left(\sim 800 \mathrm{~m} \mathrm{~s}^{-1}\right)$ and refraction $\left(\sim 4000 \mathrm{~m} \mathrm{~s}^{-1}\right)$. From this we inferred that the depth of the first layer is approximately $8 \mathrm{~m}$. In DAS, there is more coherence in the moveout of the waveform, and it appears that the direct wave is about $2250 \mathrm{~m} \mathrm{~s}^{-1}$. We hypothesize that this seems to be the average of the direct arrival and refraction on the geophone gather. We identified four possible reflections (red arrows) that are kinematically consistent in both the geophone and DAS data in Fig. 5. Dynamically, these phases in DAS are more continuous and coherent, possibly owing to the continuous nature of the overlapping DAS channels, compared to discrete geophones.

Ground roll (surface waves $\sim 370 \mathrm{~m} \mathrm{~s}^{-1}$ ) is clear in the geophone gather but not manifested in DAS. Results on this have been mixed in different experiments. Martin et al. (2017b) conducted an active-source seismic experiment with fiber in underground telecommunication conduits and did not report strong ground roll that was clear on $3 \mathrm{C}$ nodes. However, Spikes et al. (2019) conducted an active-source seismic experiment to compare geophone and DAS data where the fiber was left on the surface of the ground. Their data showed clear surface wave moveout in DAS. There are several possibly hypotheses behind the lack of surface waves in 

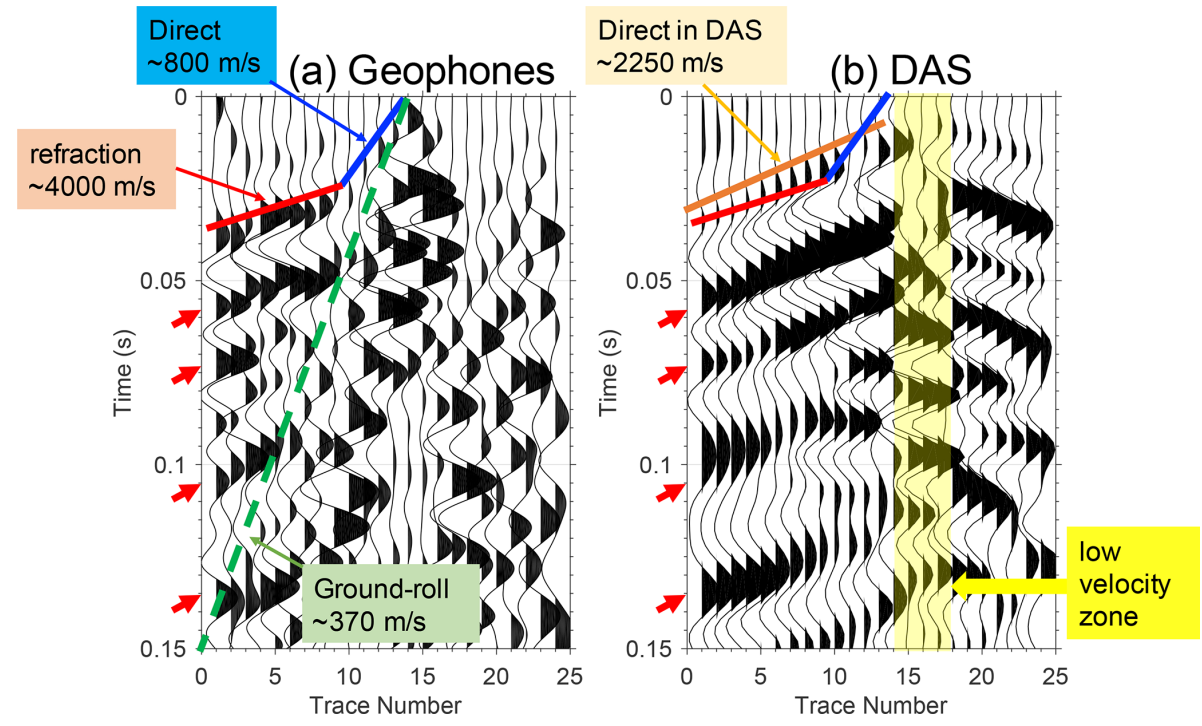

Figure 5. Geophone (a) and DAS (b) active-source shot gather.

Fig. 5b, for example fiber buried at shallow depths $(\sim 1 \mathrm{~m})$ in the conduit and loose contact of fiber to the conduit.

Another unique and interesting observation on DAS is that the energy around the hammer shot shifted down (highlighted yellow zone), which is likely the trapped waves propagated vertically inside a low-velocity zone (e.g., sinkhole in this area). This observation echoes the study of fault-zonetrapped waves using dense seismic geophones and DAS by Jousset et al. (2018). The ability to detect such signals is a benefit of using dense sensors like DAS. We suggest that further seismic wave modeling should be conducted to verify the presence of the low-velocity zone.

\section{Ground motion induced by natural sources}

Several prior studies have demonstrated that earthquake signals can be recorded by DAS with newly installed fiber (Lindsey et al., 2017; Biondi et al., 2017; Wang et al., 2018) and dark fiber in the conduit (Lindsey et al., 2017; AjoFranklin et al., 2019; Yu et al., 2019). Here we report observations of earthquakes and thunderquakes from the Penn State FORESEE array. We further include a comparison of the array to standard seismometers at both low and high frequencies, a necessary step to verify the broadband response of any new DAS array (Lindsey et al., 2020a).

\subsection{Earthquake}

Figure 6 shows DAS recordings of four earthquakes (Peru M 8.0 earthquake on 26 May 2019, Ridgecrest M7.1 earthquake on 6 July 2019, Tennessee (TE) M 3.8 earthquake on 20 January 2020 and PA M 1.1 earthquake on 27 August 2019). We applied the band-pass filtering to both PSRS and DAS seismograms. All top panels show seismograms (par- ticle velocity) from nearby seismic station PSRS (Nyquist frequency: $50 \mathrm{~Hz}$ ) as references and one trace (100th sensor) from DAS, while the bottom in Fig. 6 shows full DAS recordings of 2137 channels. DAS of the Peru M 8.0 earthquake shows strong $\mathrm{P}$ waves, $\mathrm{S}$ waves and surface waves. It serves well to calibrate kinematics and dynamics of seismograms in the above section. While, for the Ridgecrest M7.1 earthquake, $\mathrm{P}$ waves are relative invisible in DAS, $\mathrm{S}$ waves are clearly identified at 03:27:30 UTC. Surprisingly, DAS has strong $\mathrm{S}$ waves, and seismometer surface wave energy is much stronger than S-wave energy. The Tennessee M 3.8 earthquake appears weak in energy in DAS recordings in Fig. 6c. Due to rush hour (15:10 LT), this DAS record is very noisy and contaminated with traffic noise (linear events), but surface waves are still identifiable. The last event, shown in 6d, was the PA M 1.1 earthquake near State College (10 km away from the array) in Pennsylvania. Two body wave phases are clearly visible, and surface waves likely follow $\mathrm{S}$ waves.

\subsection{Thunderquake}

While there have been other examples of DAS arrays using existing telecommunication infrastructure on land, these have been concentrated in the western USA, which rarely experiences thunderstorm lightning (Changnon, 2001). Thus, in deploying an array in the eastern USA, we had a unique opportunity to study how thunder and lightning couple to the ground to induce seismic waves. Prior studies with a single seismometer or a small handful of seismometers have observed that thunder can induce ground motion (Lin and Langston, 2007), but to our knowledge this has never been studied with a large dense array (Zhu and Stensrud, 2019). On 15 April 2019, a severe thunderstorm crossed over the array, verified by the National Lightning Detection Network. 
(a) Peru M8.0 earthquake

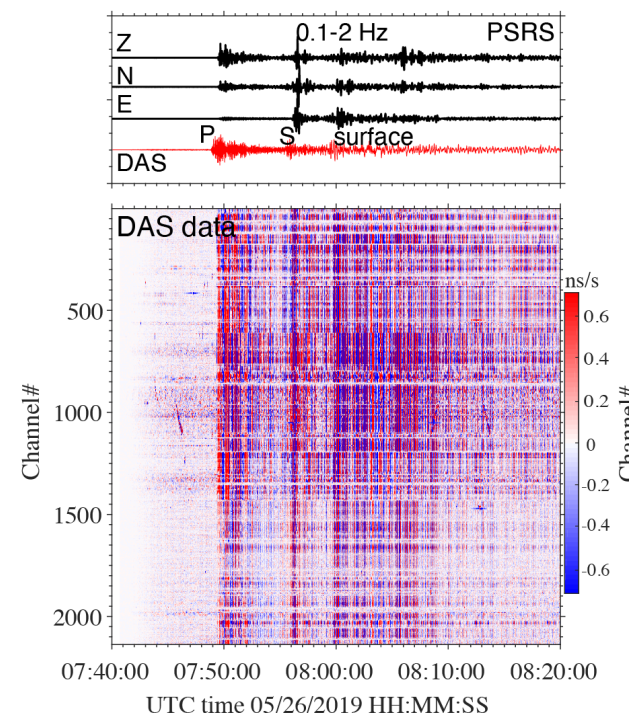

(c) TE M3.8 earthquake

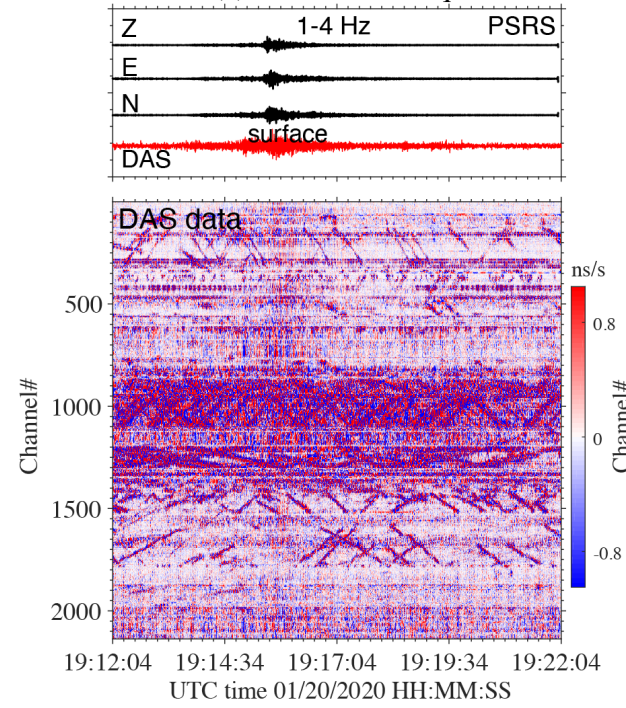

(b) Ridgecrest M7.1 earthquake
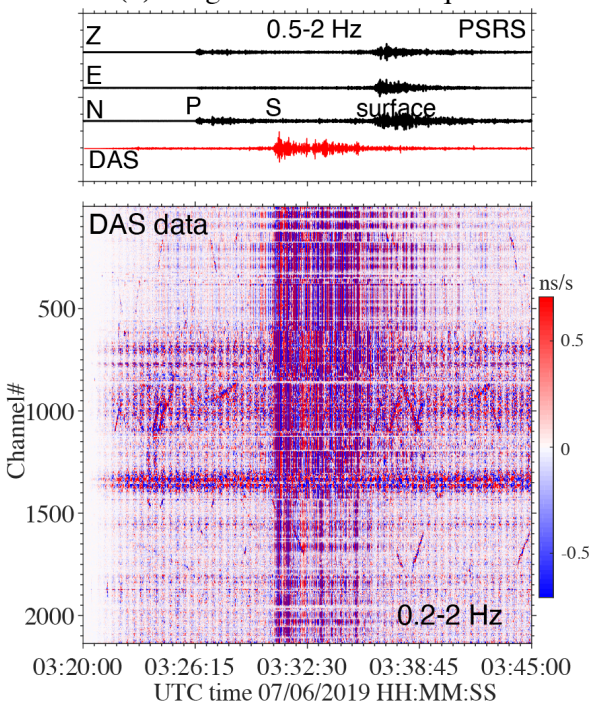

(d) PA M1.1 earthquake
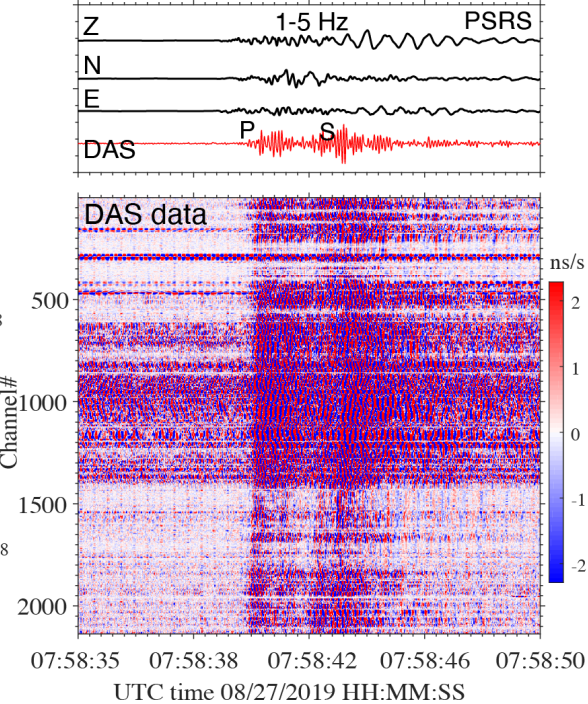

Figure 6. DAS recordings of earthquakes: (a) Peru M 8.0 earthquake on 26 May 2019; (b) Ridgecrest M 7.1 on 6 July 2019 ; (c) Tennessee M 3.8 on 20 January 2020, and (d) PA M 1.1 on 27 August 2019. The top panel shows reference seismograms from nearby seismic station PSRS. The color bar scale hereafter is in raw DAS output.

We were able to detect clear thunder events across the array, one of which that occurred on 15 April 2019 is pictured in Fig. 7 (Zhu and Stensrud, 2019). Figure 7a shows 2 min raw recordings of six (e4-e10) events between03:33 and 03:35 UTC. Spectrograms of two channel traces (black traces overlain in Fig. 7a) show the spatial variation of recordings between two channels. We hypothesize that this recorded seismic energy is induced by thunder and/or lightning electromagnetic waves coupling to the ground to induce surface waves propagating in the shallow subsurface. The spatial variation could suggest the spatial attenuation of the shallow subsurface layer. The travel time moveout selected enables us to characterize the thunderquake events (Zhu and Stensrud, 2019) and wave propagation across the FORESEE array. Even State College also be reconstructed from DAS data. Up to now, we have manually identified more than 120 thunderquakes from other four severe thunderstorms from April to August 2019.

Figure 8 shows the average power spectral density (PSD) of raw DAS recordings of the earthquake and thunderquake events in Figs. 6 and 7, which is computed by averaging the power spectrum of each channel for all channels. The Nyquist frequency of DAS recordings is 250 vs. a $50 \mathrm{~Hz}$ Nyquist frequency of seismometers. Distant earth- 


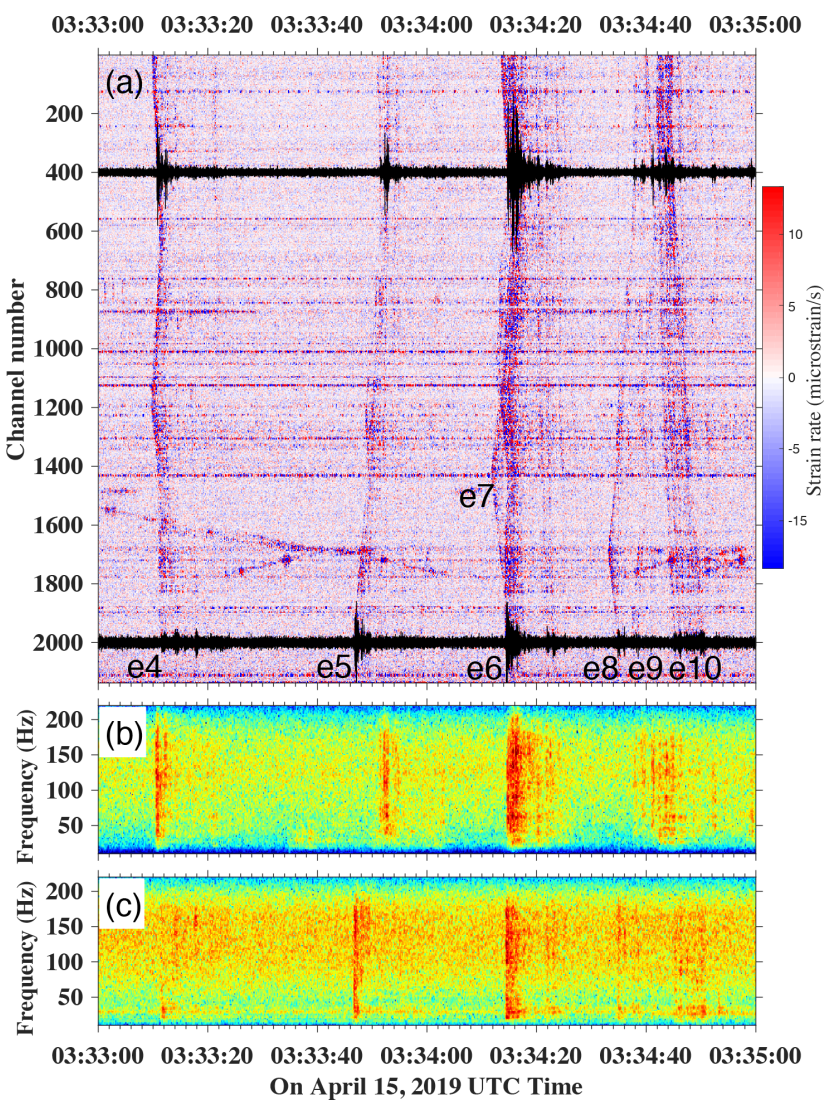

Figure 7. DAS recordings of (a) thunderquake events on 15 April 2019. Two traces (channels 400 and 2000) are overlaid. Panels (b) and (c) show DAS spectrograms $(0-40 \mathrm{~dB})$ computed for channel 400 and channel 2000, respectively.

quakes were downsampled in preprocessing. We observed low-frequency local and regional earthquakes (PA M 1.1 and TE M 3.3) $(0.05-20 \mathrm{~Hz})$ and a long-period global earthquake $(0.01-1 \mathrm{~Hz})$. The peak of thunderquakes lies in the range of high frequency $(10-130 \mathrm{~Hz})$. We can conclude that the FORESEE DAS fiber is able to record the broadband quakes $(0.01-250 \mathrm{~Hz})$.

\section{Effect of geometry on measurement polarity}

We found that in many cases channels oriented in orthogonal directions show a polarity flip following the $S$ waves. Figure 9 shows an example of this polarity flip from the Peru M 8.0 earthquake (Fig. 6a). The far-field recording of the seismic waves, which can be considered as plane waves, should be constant over the entire array. However, after the arrival of $\mathrm{S}$ waves, two straight sections of fibers in different directions at the corner (see $\mathrm{BH} 1$ and $\mathrm{BH} 2$ in Fig. 3a) show the waveforms with opposite signs, while the polarity in the window of $\mathrm{P}$ waves remains unchanged. This pattern is caused by the axial sensitivity of DAS and the tensor na-

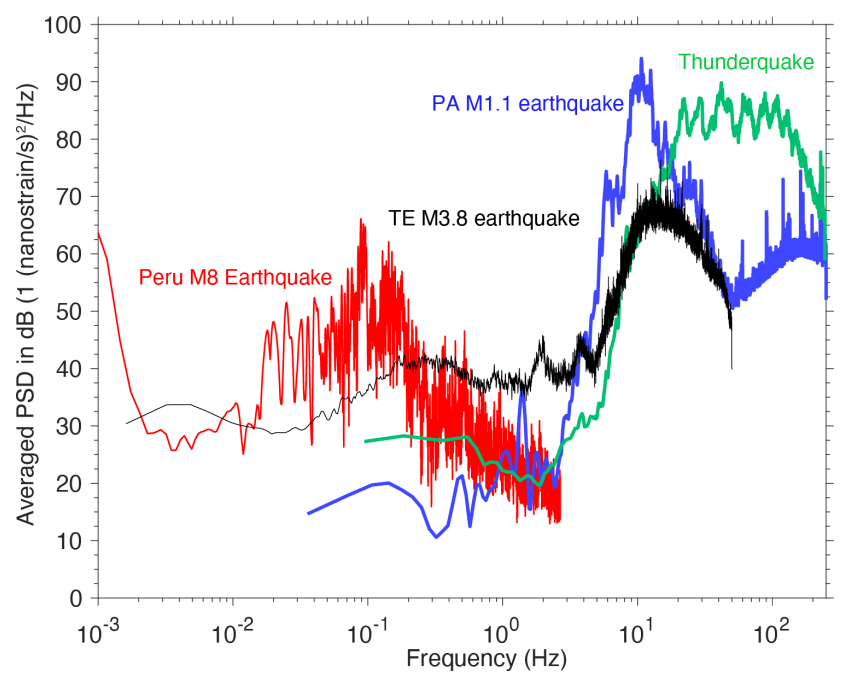

Figure 8. Averaged power spectral density of DAS recordings of earthquakes and thunderquakes.

ture of strain measurements, and this observation is in agreement with prior observations and theoretical modeling (Lindsey et al., 2017; Martin, 2018; Martin et al., 2018b). DAS only records the strain rate along the fiber and has different response of $\mathrm{P}$ and $\mathrm{S}$ waves since they have different polarization. For incoming waves with particle motion in the same direction as propagation (e.g., $\mathrm{P}$ waves, Rayleigh waves), the recordings of two orthogonal fibers have the same polarity, but the amplitude is determined by the wave propagation direction. For waves with particle motion perpendicular to the fiber direction (e.g., $\mathrm{S}$ waves, Love waves), the amplitude is the same, but the polarity flips (Lindsey et al., 2017). This understanding of the polarity and amplitude effects of geometry allows us to approximately predict the response of the fiber in different directions to some known wave mode arrivals.

\section{Urban anthropogenic seismic sources}

The high degree of human activities in urban environments results in a large level of background vibrations that has attracted scientific interest in terms of subsurface characterization and hazard mapping (Díaz et al., 2017). Prior urban DAS studies have shown anthropogenic sources of noise, such as pumping systems (plumbing, heating or air conditioning) and vehicle traffic (Martin et al., 2018a). While vehicle moving signals can be identified by the linear moveout events and the passing speed is calculated by the slope of the signal, this section will present the DAS recordings of other interesting anthropogenic sources not previously reported. 

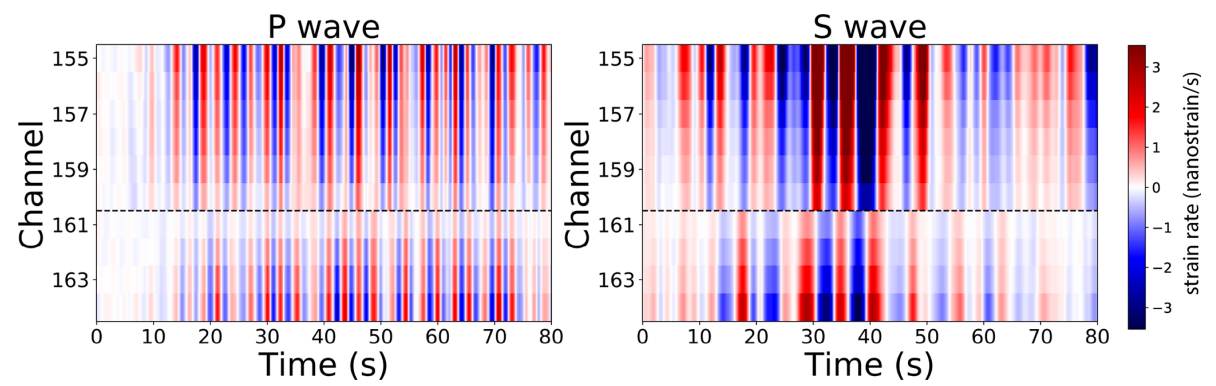

Figure 9. P-wave and S-wave traces observed in two orthogonal fibers (marked by dashed line in Fig. 3a). There is a polarity flip of the S wave.

(a)

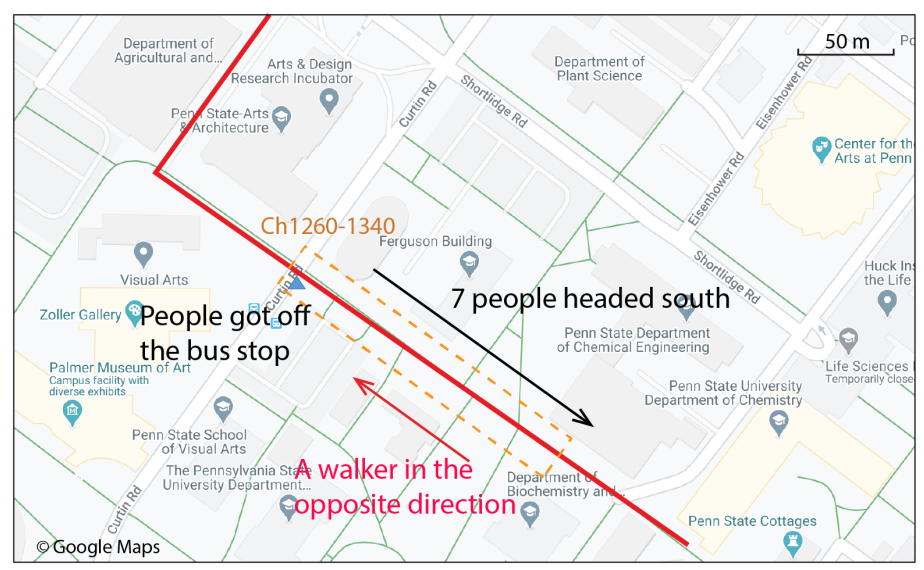

(b)

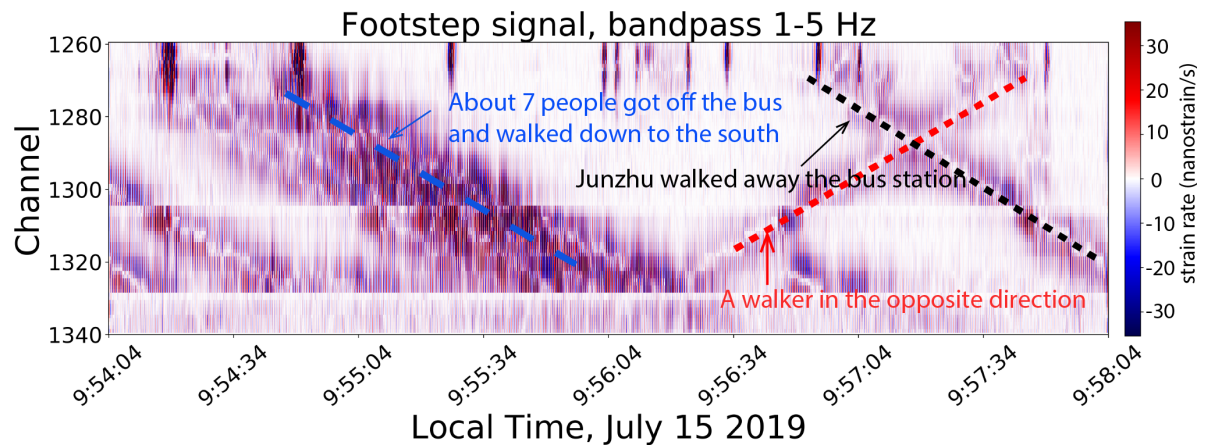

Figure 10. (a) Map of the array and walker information; (b) band-passed data between 1 and $5 \mathrm{~Hz}$. Dashed black and blue lines indicate a walker (author) and a group of walkers from the school bus walking away from the bus station (around channel 1270) along the fiber path, and later a walker moved towards the station. The slope of lines gives the walking speed of about $1.2 \mathrm{~m} \mathrm{~s}^{-1}$.

\subsection{Footsteps}

It is surprising that, despite relying on just friction and gravity for coupling existing fiber optics to conduits, we were able to detect walking individuals in Fig. 10. After band-pass filtering $(1-5 \mathrm{~Hz})$, clear footstep signals are recorded by a subset of the array beneath a straight path without moving cars. With offsets in this dense array in the bottom panel of Fig. 10, we are able to identify the walking direction and whether vibrations are caused by individuals or groups (see examples of individuals and groups in Fig. 10); the second author (dashed black line) following a group of people (blue line) who departed from the bus station (around channel 1270) and headed south; and later a walker (red line) who moved in the opposite direction towards the bus station, corresponding well with the timings of in-person field observations made on 15 July 2019 (Fig. 10). We can also estimate the walking speed as about $1.2 \mathrm{~m} \mathrm{~s}^{-1}$ from the slope of dashed lines. To be general, we analyze the power spectral density of $1 \mathrm{~min}$ data at noon (across channels 800- 


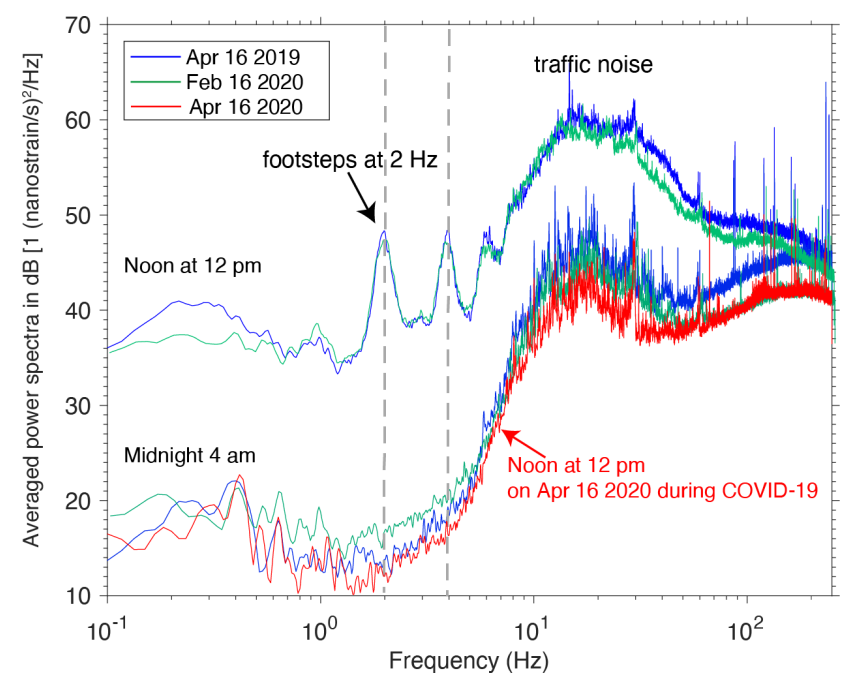

Figure 11. The power spectra density of 1 min DAS data on three days (16 April 2019, 16 February 2020, and 16 April 2020) shows that signals at noon are much stronger than signals at 04:00 UTC. Additionally there are distinct peaks that appear in the signals from midday, particularly strong at 2 and $4 \mathrm{~Hz}$. Traffic noises correspond to $>5 \mathrm{~Hz}$ signals. During the COVID-19 pandemic the power spectra at noon are as low as at nighttime, and no footstep signals are found.

2137, above central campus) from three very different days (16 April 2019, 16 February 2020 and 16 April 2020). Figure 11 shows significant peaks at around 2.0 and $4.0 \mathrm{~Hz}$ (harmonic), while they disappear at midnight. This $2.0 \mathrm{~Hz}$ signal corresponds to walking steps on campus, equivalent to 120 steps per minute, which is similar to the people walking on shopping floors with an average frequency of $2.0 \mathrm{~Hz}$ and a velocity of $1.4 \mathrm{~m} \mathrm{~s}^{-1}$ (Pachi and Ji, 2005), slower than marathon runners with $2.8 \mathrm{~Hz}$ (Diaz et al., 2020). Not surprisingly, these footstep signals do not show up on 16 April 2020 during the COVID-19 crisis after the stay-at-home order in PA on 1 April 2020. And the noise power spectra level is close to that at midnight. Spatially, we also calculated the power spectra of data at channels 1-600 (on the edge of campus), and the peaks at 2 and $4 \mathrm{~Hz}$ are not found (not shown here). We can see that DAS recordings provide the spatial and temporal distribution of the footsteps that may be useful for designing and analysing campus traffic.

For the goals of the FORESEE array, these footsteps are likely to hinder efforts towards subsurface imaging with ambient-noise interferometry, so we are interested in removing these signals prior to imaging. Further, as DAS arrays are deployed in a wider variety of locations, there may be areas where removing the footsteps is needed to ensure privacy of people in the area. We recently developed a convolutional neural network to automatically identify pedestrian footsteps, the first step towards removing these signals (Jakkampudi et al., 2020).

\subsection{Mining blast}

Several mining sites around State College (Fig. 12) provide well-repeatable blast sources for further calibration and nearsurface monitoring. The distances of four mining sites (site 1 , site 2, site 3 and site 4 ) to the campus are about 31 , 41,84 and $15 \mathrm{~km}$, respectively. The reference seismic station indicated by the blue triangle is about $10 \mathrm{~km}$ southwest from State College. Figure 13 shows three quarry blast events, one each from sites 1,2 and 3 . With proper bandpass filtering $(1-5 \mathrm{~Hz})$, these events are clearly visible in the noisy records since they were occurring during traffic hours. Their recordings are kinematically consistent with reference seismograms by $1-2.5 \mathrm{~Hz}$ band-pass filtering. Strong surface waves are identified despite these explosive sources. In 2019 there are several hundred repeatable blast events cataloged from these sites, which could allow yearly near-surface monitoring of geotechnical engineering activities (Fang et al., 2020) and/or hydrological systems owing to a significant ground water level variation. One strong event, shown in Fig. 14, was recorded on 14 May 2019 from site 4 (Pleasant Gap, PA). Since this event has equal-distance seismic station PSRS and DAS (see Fig. 12), there is a $2 \mathrm{~s}$ time delay between two data. Figure 14a shows high-frequency $\mathrm{P}$ and $\mathrm{S}$ waves $(10-20 \mathrm{~Hz})$. In Fig. 14b, we can see strong lowfrequency transverse motions. As in previous observations, this low-frequency transverse wave exhibits flipped polarity at the orthogonal fiber locations (e.g., indicated by arrows in channels 170 and 600), which is either a SH or Love wave and was also observed in previous DAS recordings from the Stanford DAS array (Martin, 2018; Fang et al., 2020).

\subsection{Live music}

In general, seismic sources that only couple to the ground through sound often have weaker coupling, and prior studies of active-seismic-source experiments detected by buried fiber optics did not show air waves (Martin et al., 2017b). However, our DAS data recorded distinctive signals corresponding to live music during the 26 April 2019 Penn State Movin' On music festival (Zhu et al., 2019). The live music stage was directly above channel 120-150. Figure 15 shows an example of 20 min DAS recordings of four songs - "Welcome to Your Life", "Cannonball", "Good Morning", "Ways to Go" - based on the timings of the concert playlist. Figure $15 \mathrm{~b}$ shows large variations of recorded seismic amplitudes, even within the different parts of a single song. The break between songs is easily identified as a gap between waveforms and spectrograms in Fig. 15c. The spectrogram of trace 130 shows that different songs result in characteristic spectra composed of narrow and evenly spaced energy (zoomed details in Fig. 15d). We can detect sustained notes in the bass range $(40-140 \mathrm{~Hz})$. Played back and visualized with the IRIS SeisSound tool, these signals are clearly fat bass riffs with much of the energy below $100 \mathrm{~Hz}$ (refer to 


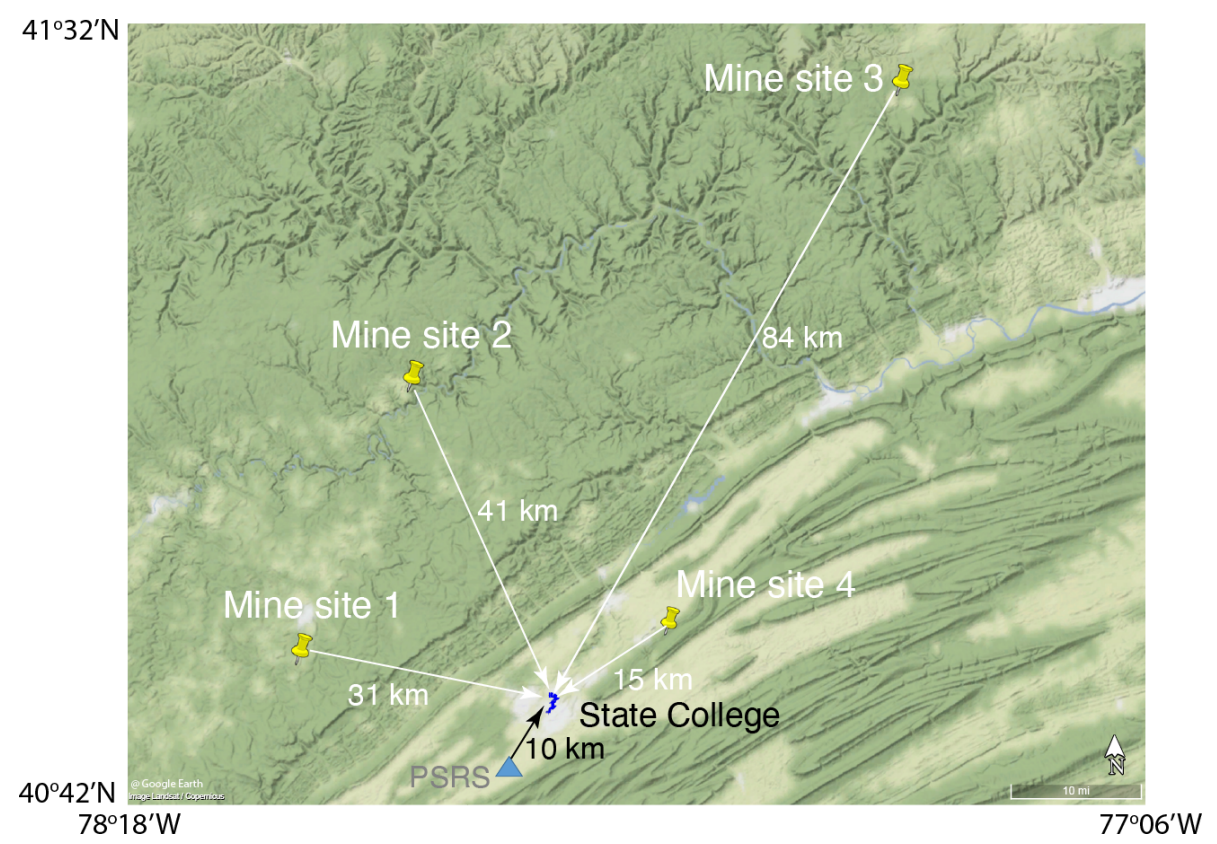

Figure 12. Map of geographical distribution of blast sites (site 1, site 2, site 3 and site 4) around State College. The distances to State College are about $31,41,84$, and $15 \mathrm{~km}$, respectively. Seismic station PSRS, indicated by the blue triangle, is about $10 \mathrm{~km}$ southwest away from State College. Short blue line is the FORESEE array.
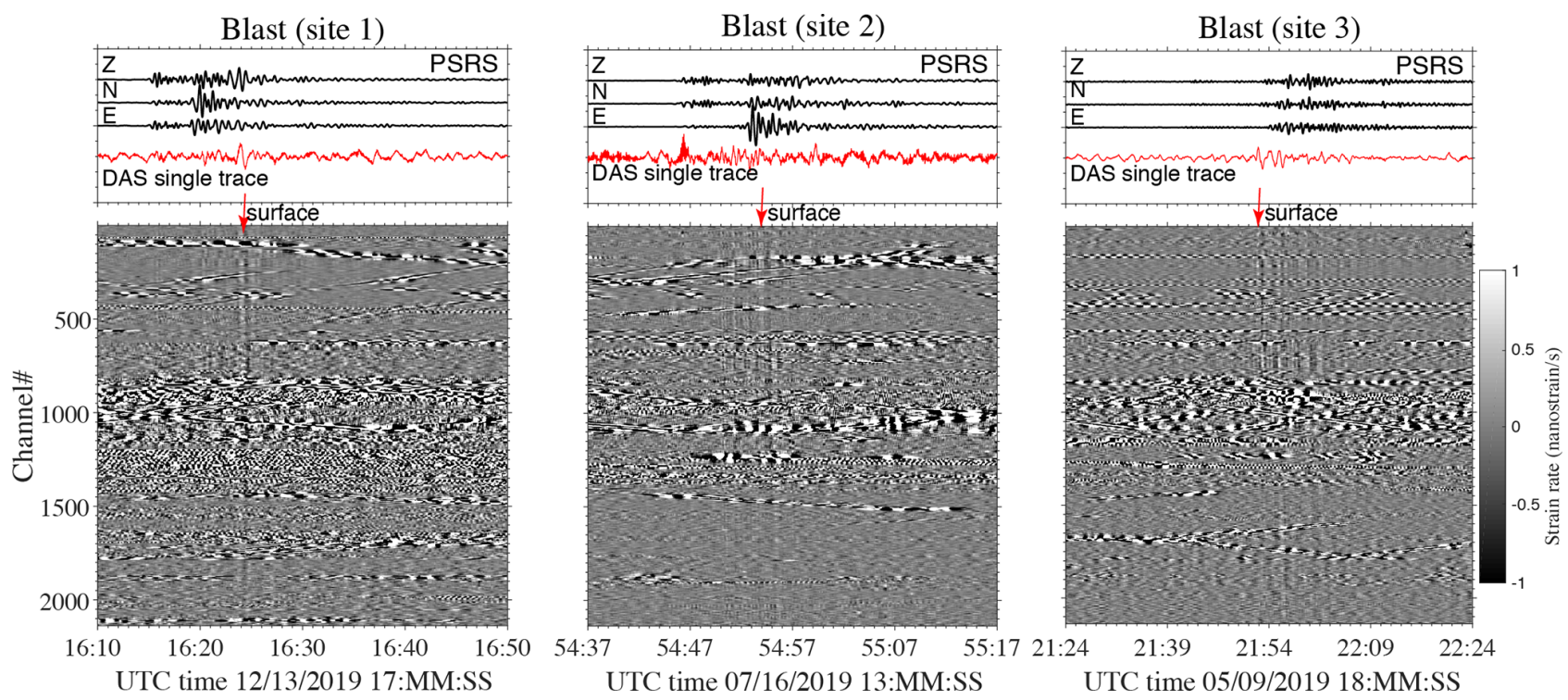

Figure 13. Seismic station (PSRS) and DAS recordings of three quarry blast signals from three mining sites (site 1, site 2 and site 3 ). Their magnitudes from the Pennsylvania State Seismic Network catalog are M 1.3, M 1.7, and M 2.0, respectively. Red arrows indicate strong surface wave arrivals.

audio of the song "Good Morning" in the supporting materials of Zhu, 2020). This is not the first time seismometers have detected the bass line of concerts; Díaz et al. (2017) showed similar results from a single broadband seismic station during a Bruce Springsteen concert in Barcelona. The difference here is the densely sampled spatial data, which enable us to see that these signals were clearly sensed more than half a kilometer away in Fig. 16. Wang et al. (2020) reported similar seismic recordings of parade floats and bands by the Pasadena distributed acoustic sensing array. 

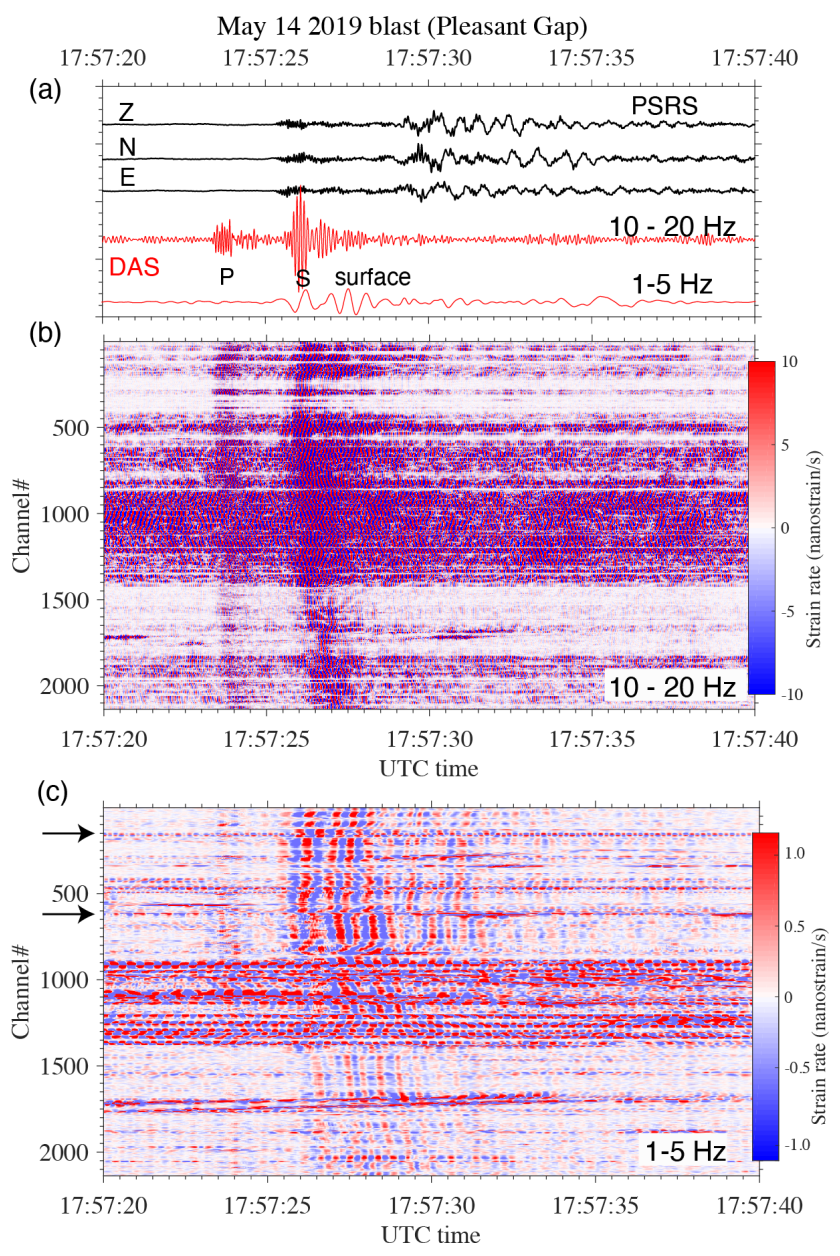

Figure 14. Seismic station (PSRS) and DAS recordings of one blast (M 1.0) from site 4 (see Fig. 12), about $10 \mathrm{~km}$ away from State College. (a) Three-component seismogram (band-pass filtering, 1$15 \mathrm{~Hz}$ ) and 100th DAS trace with filtering by two different bandpass filters. DAS recording after (b) band-pass filtering $(10-20 \mathrm{~Hz})$ and (c) band-pass filtering $(1-5 \mathrm{~Hz})$.

\section{Discussion}

This experiment adds a unique geological environment and new set of questions to the growing body of research on the use of DAS in populated areas and around infrastructure. While these new sensing systems have some limitations, they also have a number of benefits and are enabling a wider variety of applications in new locations. In particular we are seeing their value in the eastern USA, and our investigations suggest DAS systems could play a significant role in the broader ecosystem of smart-city development.

A primary limitation of DAS arrays at present is that each channel records the axial strain rate. On a straight fiberoptic cable this is a single component of the strain tensor. While some fit-for-purpose installations for energy production or $\mathrm{CO}_{2}$ sequestration have utilized helical fibers to instead record a mixture of strain components (Kuvshinov,
2016), the cost of producing these specialty cables is typically too high for engineering and environmental geophysics. Thus, dark-fiber arrays must find creative methods to utilize different directions within an array made up of straight segments. Dark-fiber DAS acquisitions have the additional limitation that we currently have only a small understanding of the effects of the installation on signals (Papp et al., 2017; Martin et al., 2017a; Ajo-Franklin et al., 2019).

Despite those limitations, DAS technology has enabled dense wide-aperture sensor arrays with very little labor, approaching industry-scale exploration. In particular, the density of sensors has enabled a wider variety of methods to image subsurface structures and properties, including full waveform migration and inversion (Egorov et al., 2018) and receiver function Moho imaging (Yu et al., 2019). For nearsurface imaging, Zhang et al. (2020) successfully applied wave-equation dispersion inversion to ambient-noise DAS data with careful processing. At the FORESEE array, the combination of wide aperture and high density enabled full waveform modeling and time-reversal imaging to characterize thunderquake sources as a new source of strong local seismic energy (Zhu and Stensrud, 2019).

In applications where seismic energy sources of interest are spread over wide areas, particularly when using earthquakes or thunderquakes as sources for imaging, fiber optics will enable extensive coverage. This is particularly important in the eastern USA, which has relatively low rates of seismicity, meaning fewer regional earthquakes and less traditional instrument coverage to capture high-frequency content. This leads to limitations in high-resolution regional and urban near-surface models, so other seismic energy sources such as thunderquakes could be particularly useful in developing $3 \mathrm{D}$ regional tomography maps of the shallow crust beneath local regions in the eastern USA.

Moving forward, DAS arrays utilizing existing telecommunication fibers are making it much more cost-effective and practical in urban areas than installing traditional instrument arrays, and DAS arrays can play an increasing role in development of resilient, sustainable cities. This includes geophysical and geotechnical applications: near-surface imaging for planning stable structures, measuring ground motion due to natural sources, monitoring subsidence, identifying major sources of seismic energy, understanding urban hydrological systems and locating geohazards. The value of DAS has been recognized in inaccessible and harsh environments, enabling offshore ocean observations (Lindsey et al., 2019; Williams et al., 2019), as well as Arctic monitoring as climate change threatens the stability of permafrost under infrastructure (Martin et al., 2016; Ajo-Franklin et al., 2017) and leads to degradation of glaciers (Walter et al., 2020). We anticipate that it will also play an important role in the critical zone community to image near-surface heterogeneous Earth materials, varying spatially at the scale of meters or even smaller and temporally from hours to years. Further, unprecedented 

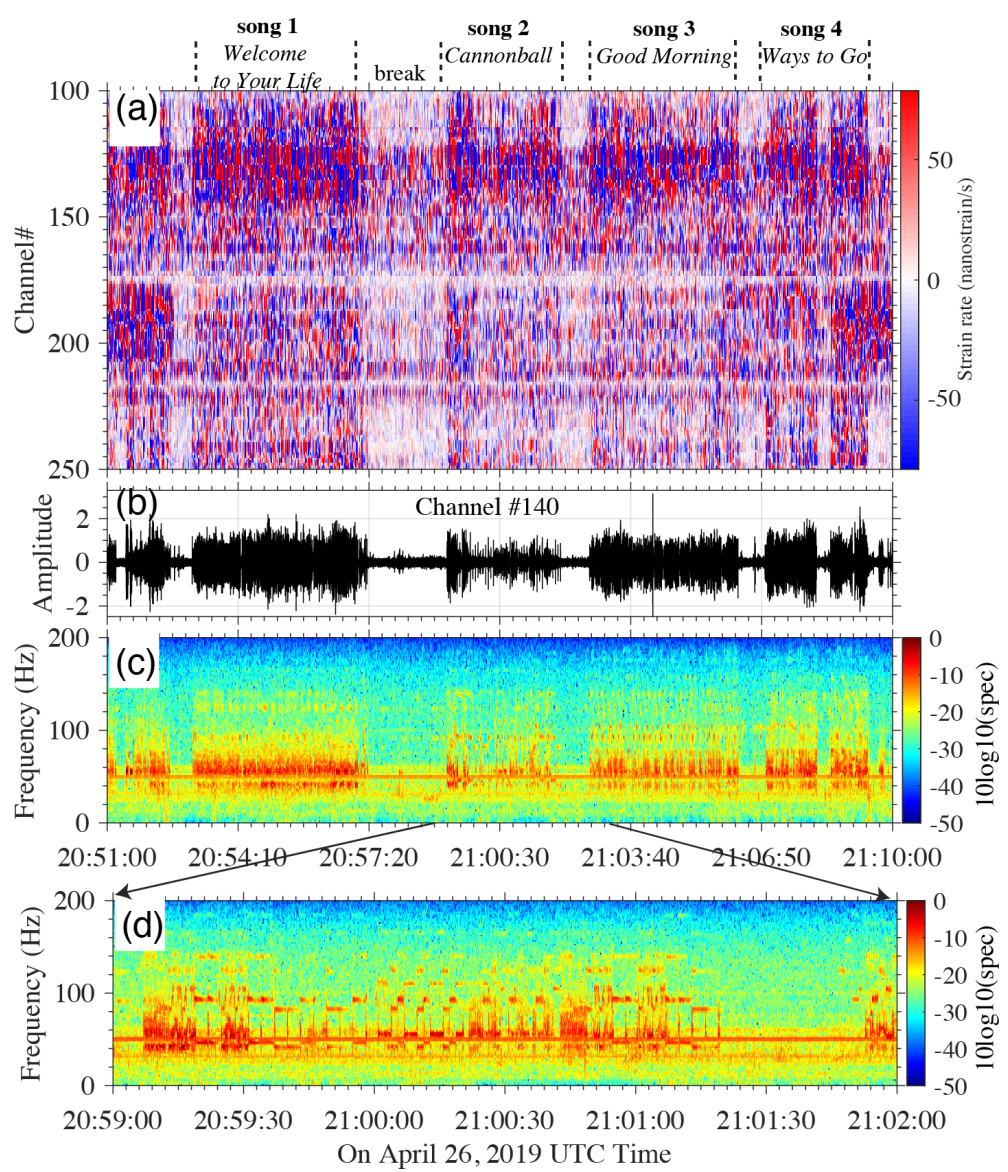

Figure 15. (a) DAS recording of concert music after band-pass filtering (1-150 Hz). (b) One trace at DAS channel 140 and (c) its spectrogram.

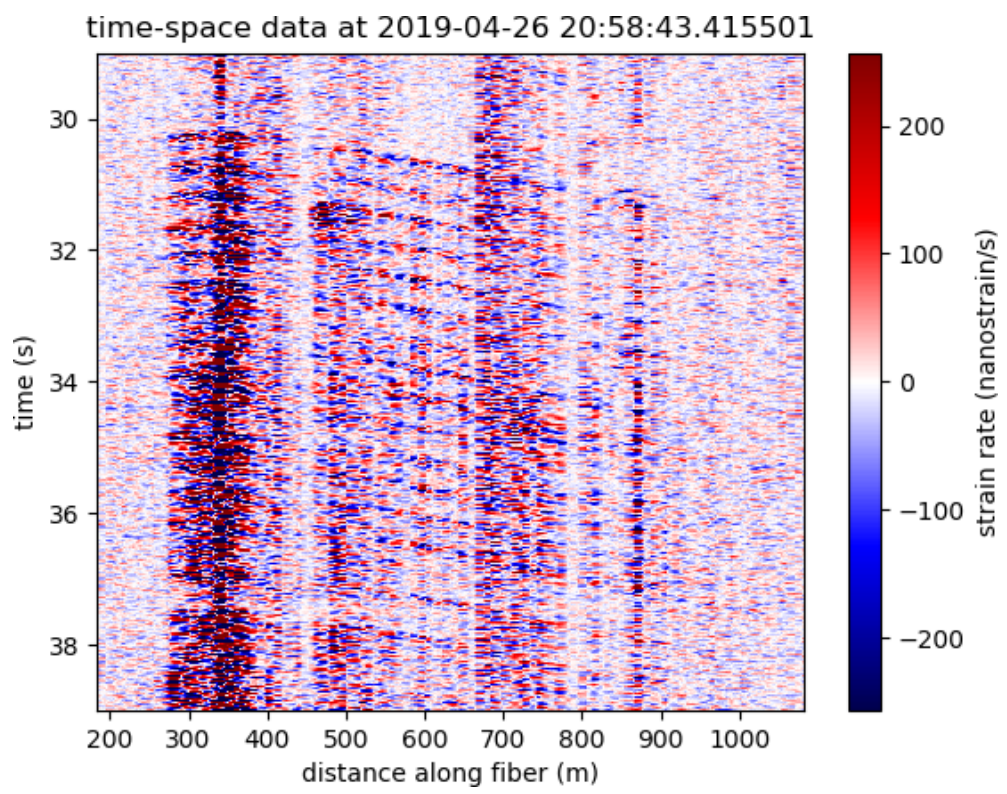

Figure 16. A short segment of seismic data from the beginning of song 2 in Fig. 15 shows evenly spaced vibrations propagating away from the stage and detected over half a kilometer away. 
large-volume DAS data provide an opportunity to test new data analytic algorithms.

However, the economics of deploying fiber-optic systems are unlikely to be motivated by geoscience alone, and we must understand DAS arrays as multipurpose systems with a variety of applications in engineering and urban planning. In general, detection and identification of small events in the noisy urban environment has been challenging, but we can take advantage of the dense and continuous recordings provided by DAS to isolate these noises to understand and remove them. In particular, both unsupervised and supervised machine learning methods have been used to isolate car signals and footsteps for removal (Martin et al., 2018a; Jakkampudi et al., 2020). Car detection can even yield insights into temporally and spatially varying patterns of human activities relevant to public health and urban planning (Lindsey et al., 2020b). Additional future applications beyond geophysics should be studied, including traffic monitoring and redirection (without requiring private cell phone data), gunshot array detection, industrial noise pollution monitoring and subsurface water utility monitoring.

\section{Conclusions}

We have deployed the FORESEE array using existing fiber optics under the Penn State University campus in Pennsylvania, USA, and acquired $75 \mathrm{~TB}$ of data over the course of about $360 \mathrm{~d}$ since 5 April 2019. While this array confirms findings from earlier dark-fiber arrays in the western USA that such a system can record local active seismic sources and earthquakes, this is the first experiment of its kind in the eastern USA and reveals a wider range of new signals, including thunderquakes, concerts and even footsteps. The density of these broadband DAS recordings provides extraordinary resolution that enables insight into their cause and allows us to distinguish between these various signals. We anticipate that the collected FORESEE data will be able to answer relevant geoscience questions, particularly related to urban hydrology and geohazards. DAS arrays utilizing existing telecommunication fibers have the capability to sense broadband vibrations, and we conclude that DAS will potentially serve as a multipurpose system for continuous near-surface seismic monitoring in populated areas (e.g., geohazards, critical zone, permafrost, hydrology, geotechnical engineering, infrastructure management and urban planning).

Data availability. The Penn State FORESEE DAS processed waveform data will be available via Penn State Data Commons. The downsampled thunderquake data are available here: https://sites.psu.edu/tzhu/foresee/ (last access: 10 January 2020). Broadband seismic waveform data for the seismic station PSRS are retrieved from the IRIS Data Management Center (https://doi.org/10.7914/SN/PE). Figure 1 map is available under the Open Database License.
Supplement. Waveform and audio of 3 min DAS live music signals during 21:02-21:05 UTC on 26 April 2019. The supplement related to this article is available online at: https://doi.org/10.5194/se-12219-2021-supplement.

Author contributions. TZ designed the experiment, conducted data processing and analysis, and led the writing. JS managed DAS data, calibrated DAS data, and contributed to data analysis and the writing. ERM assisted in experiment planning and contributed to data analysis and the writing. All authors participated in the fieldwork.

Competing interests. The authors declare that they have no conflict of interest.

Special issue statement. This article is part of the special issue "Fibre-optic sensing in Earth sciences". It is not associated with a conference.

Acknowledgements. We really appreciate Chris Marone for his warm support in convincing the Penn State Institute of Natural Gas Research to provide seed money to the FORESEE array. We also appreciate our collaborators Patrick Fox, Dave Stensrud, and Andy Nyblade for their contribution of the FORESEE array. We would also like to thank Todd Myers and Ken Miller at Penn State University and Thomas Coleman from Silixa, who helped set up the fiber-optic DAS array. We thank two reviewers, Baoshan Wang and an anonymous reviewer, for their valuable comments, which helped us to improve the paper. Eileen R. Martin was supported by DOE Award No. DE-SC0019630 and by DOE Award No. DE-FOA0001990.

Financial support. This research has been supported by the Penn State Institute of Environment and Energy Seed Grant and Institute of Natural Gas Research.

Review statement. This paper was edited by Gilda Currenti and reviewed by two anonymous referees.

\section{References}

Ajo-Franklin, J., Dou, S., Daley, T., Freifeld, B., Robertson, M., Ulrich, C., Wood, T., Eckblaw, I., Lindsey, N., Martin, E., and Wagner, A.: Time-lapse surface wave monitoring of permafrost thaw using distributed acoustic sensing and a permanent automated seismic source, in: 2017 SEG International Exposition and Annual Meeting, Society of Exploration Geophysicists, 2017.

Ajo-Franklin, J. B., Dou, S., Lindsey, N. J., Monga, I., Tracy, C., Robertson, M., Tribaldos, V. R., Ulrich, C., Freifeld, B., Daley, T., and add Li, X.: Distributed acoustic sensing using dark fiber for near-surface characterization and broadband seismic event detection, Sci. Rep.-UK, 9, 1-14, 2019. 
Bansah, K. J.: Imaging and mitigating karst features, 2018.

Biondi, B., Martin, E., Cole, S., Karrenbach, M., and Lindsey, N.: Earthquakes analysis using data recorded by the Stanford DAS array, in: 2017 SEG International Exposition and Annual Meeting, Society of Exploration Geophysicists, 2017.

Brantley, S. L., Holleran, M. E., Jin, L., and Bazilevskaya, E.: Probing deep weathering in the Shale Hills Critical Zone Observatory, Pennsylvania (USA): the hypothesis of nested chemical reaction fronts in the subsurface, Earth Surf. Proc. Land., 38, 1280-1298, 2013.

Changnon, S. A.: Damaging thunderstorm activity in the United States, B. Am. Meteorol. Soc., 82, 597-608, 2001.

Daley, T., Miller, D., Dodds, K., Cook, P., and Freifeld, B.: Field testing of modular borehole monitoring with simultaneous distributed acoustic sensing and geophone vertical seismic profiles at Citronelle, Alabama, Geophys. Prospect., 64, 1318-1334, 2016.

Daley, T. M., Freifeld, B. M., Ajo-Franklin, J., Dou, S., Pevzner, R., Shulakova, V., Kashikar, S., Miller, D. E., Goetz, J., Henninges, J., and Lueth, S.: Field testing of fiber-optic distributed acoustic sensing (DAS) for subsurface seismic monitoring, The Leading Edge, 32, 699-706, 2013.

Díaz, J., Ruiz, M., Sánchez-Pastor, P. S., and Romero, P.: Urban seismology: On the origin of earth vibrations within a city, Sci. Rep.-UK, 7, 1-11, 2017.

Diaz, J., Schimmel, M., Ruiz, M., and Carbonell, R.: Seismometers Within Cities: A Tool to Connect Earth Sciences and Society, Front. Earth Sci., 8, 9, https://doi.org/10.3389/feart.2020.00009, 2020.

Dou, S., Lindsey, N., Wagner, A. M., Daley, T. M., Freifeld, B., Robertson, M., Peterson, J., Ulrich, C., Martin, E. R., and AjoFranklin, J. B.: Distributed acoustic sensing for seismic monitoring of the near surface: A traffic-noise interferometry case study, Sci. Rep.-UK, 7, 1-12, 2017.

Egorov, A., Correa, J., Bóna, A., Pevzner, R., Tertyshnikov, K., Glubokovskikh, S., Puzyrev, V., and Gurevich, B.: Elastic fullwaveform inversion of vertical seismic profile data acquired with distributed acoustic sensors, Geophysics, 83, R273-R281, 2018.

Fang, G., Li, Y. E., Zhao, Y., and Martin, E. R.: Urban Near-surface Seismic Monitoring using Distributed Acoustic Sensing, Geophys. Res. Lett., 47, e2019GL086115, https://doi.org/10.1029/2019GL086115, 2020.

Jakkampudi, S., Shen, J., Li, W., Dev, A., Martin, E. R. Zhu, T., and Martin, E. R.: Footstep detection in urban seismic data with a convolutional neural network, The Leading Edge, 39, 654-660, 2020.

Jousset, P., Reinsch, T., Ryberg, T., Blanck, H., Clarke, A., Aghayev, R., Hersir, G. P., Henninges, J., Weber, M., and Krawczyk, C. M.: Dynamic strain determination using fibreoptic cables allows imaging of seismological and structural features, Nat. Commun., 9, 1-11, 2018.

Kuvshinov, B.: Interaction of helically wound fibre-optic cables with plane seismic waves, Geophys. Prospect., 64, 671-688, 2016.

Lin, T.-L. and Langston, C. A.: Infrasound from thunder: A natural seismic source, Geophys. Res. Lett., 34, https://doi.org/10.1029/2007GL030404, 2007.

Lindsey, N. J., Martin, E. R., Dreger, D. S., Freifeld, B., Cole, S., James, S. R., Biondi, B. L., and Ajo-Franklin, J. B.: Fiber-optic network observations of earthquake wavefields, Geophys. Res. Lett., 44, 11-792, 2017.

Lindsey, N. J., Dawe, T. C., and Ajo-Franklin, J. B.: Illuminating seafloor faults and ocean dynamics with dark fiber distributed acoustic sensing, Science, 366, 1103-1107, 2019.

Lindsey, N. J., Rademacher, H., and Ajo-Franklin, J. B.: On the broadband instrument response of fiber-optic DAS arrays, J. Geophys. Res.-Sol. Ea., 125, e2019JB018145, https://doi.org/10.1029/2007GL030404, 2020a.

Lindsey, N. J., Yuan, S., Lellouch, A., Gualtieri, L., Lecocq, T., and Biondi, B.: City-scale dark fiber DAS measurements of infrastructure use during the COVID-19 pandemic, arXiv preprint, arXiv:2005.04861, 2020b.

Martin, E., Lindsey, N., Dou, S., Ajo-Franklin, J., Daley, T., Freifeld, B., Robertson, M., Ulrich, C., Wagner, A., and Bjella, K.: Interferometry of a roadside DAS array in Fairbanks, AK, in: 2016 SEG International Exposition and Annual Meeting, Society of Exploration Geophysicists, Dallas TX, USA, 27252729, 2016.

Martin, E. R., Biondi, B., Karrenbach, M., and Cole, S.: Ambient noise interferometry from DAS array in underground telecommunications conduits, in: 79th EAGE Conference and Exhibition 2017, vol. 2017, European Association of Geoscientists and Engineers, 1-5, 2017a.

Martin, E. R., Castillo, C. M., Cole, S., Sawasdee, P. S., Yuan, S., Clapp, R., Karrenbach, M., and Biondi, B. L.: Seismic monitoring leveraging existing telecom infrastructure at the SDASA: Active, passive, and ambient-noise analysis, The Leading Edge, 36, 1025-1031, 2017b.

Martin, E. R.: Passive imaging and characterization of the subsurface with distributed acoustic sensing, $\mathrm{PhD}$ thesis, Stanford University, 2018.

Martin, E. R., Huot, F., Ma, Y., Cieplicki, R., Cole, S., Karrenbach, M., and Biondi, B. L.: A seismic shift in scalable acquisition demands new processing: Fiber-optic seismic signal retrieval in urban areas with unsupervised learning for coherent noise removal, IEEE Signal Proc. Mag., 35, 31-40, 2018 a.

Martin, E. R., Lindsey, N., Ajo-Franklin, J., and Biondi, B.: Introduction to interferometry of fiber optic strain measurements, 2018 b.

Martin, E. R.: A scalable algorithm for cross-correlations of compressed ambient seismic noise, in: SEG International Exposition and Annual Meeting, Society of Exploration Geophysicists, 2019.

Pachi, A. and Ji, T.: Frequency and velocity of people walking, Struct. Eng., 83, 36-40, 2005.

Papp, B., Donno, D., Martin, J. E., and Hartog, A. H.: A study of the geophysical response of distributed fibre optic acoustic sensors through laboratory-scale experiments, Geophys. Prospect., 65, 1186-1204, 2017.

Parker, T., Shatalin, S., and Farhadiroushan, M.: Distributed Acoustic Sensing-a new tool for seismic applications, First Break, 32, 61-69, 2014.

Spica, Z. J., Perton, M., Martin, E. R., Beroza, G. C., and Biondi, B.: Urban Seismic Site Characterization by Fiber-Optic Seismology, J. Geophys. Res.-Sol. Ea., 125, e2019JB018656, https://doi.org/10.1029/2019JB018656, 2020.

Spikes, K. T., Tisato, N., Hess, T. E., and Holt, J. W.: Comparison of geophone and surface-deployed distributed acoustic sensing 
seismic dataGeophone and surface DAS data, Geophysics, 84, A25-A29, 2019.

Walter, F., Gräff, D., Lindner, F., Paitz, P., Köpfli, M., Chmiel, M., and Fichtner, A.: Distributed Acoustic Sensing of Microseismic Sources and Wave Propagation in Glaciated Terrain, 2020.

Wang, H. F., Zeng, X., Miller, D. E., Fratta, D., Feigl, K. L., Thurber, C. H., and Mellors, R. J.: Ground motion response to an ML 4.3 earthquake using co-located distributed acoustic sensing and seismometer arrays, Geophys. J. Int., 213, 2020-2036, 2018.

Wang, X., Williams, E. F., Karrenbach, M., Herráez, M. G., Martins, H. F., and Zhan, Z.: Rose Parade Seismology: Signatures of Floats and Bands on Optical Fiber, Seismol. Res. Lett., 91, 2395-2398 2020.

Weary, D. J.: The cost of karst subsidence and sinkhole collapse in the United States compared with other natural hazards, Proceedings of the 14th Multidisciplinary Conference on Sinkholes and the Engineering and Environmental Impacts o Karst, New Mexico, USA, https://doi.org/10.5038/9780991000951, 2015.

Williams, E. F., Fernández-Ruiz, M. R., Magalhaes, R., Vanthillo, R., Zhan, Z., González-Herráez, M., and Martins, H. F.: Distributed sensing of microseisms and teleseisms with submarine dark fibers, Nat. Commun., 10, 1-11, 2019.
Yu, C., Zhan, Z., Lindsey, N. J., Ajo-Franklin, J. B., and Robertson, M.: The potential of DAS in teleseismic studies: Insights from the goldstone experiment, Geophys. Res. Lett., 46, 1320 1328, 2019.

Zhan, Z.: Distributed Acoustic Sensing Turns Fiber-Optic Cables into Sensitive Seismic Antennas, Seismol. Res. Lett., 91, 1-15, 2020.

Zhang, Z., Alajami, M., and Alkhalifah, T.: Wave-equation dispersion spectrum inversion for near-surface characterization using fibre-optics acquisition, Geophys. J. Int., 222, 907-918, 2020.

Zhu, T.: Datasets and Results from Penn State FORESEE DAS Aarray, https://doi.org/10.17605/OSF.IO/BE7ZX, 2020.

Zhu, T. and Stensrud, D. J.: Characterizing Thunder-Induced Ground Motions Using Fiber-Optic Distributed Acoustic Sensing Array, J. Geophys. Res.-Atmos., 124, 12810-12823, 2019.

Zhu, T., Martin, E. R., and Shen, J.: New Signals in Massive Data Acquired by Fiber Optic Seismic Monitoring Under Pennsylvania State University, SEG/EAGE Workshop on Geophysical Aspects of Smart Cities, available at: https://sites.psu.edu/tzhu/ files/2019/08/ZhuMartinShen2019_fiber.pdf (last access: 10 January 2020), 2019. 